\title{
SCREENING OF MEDIA COMPONENTS AND PROCESS PARAMETERS FOR PRODUCTION OF L (+) LACTIC ACID FROM POTATO WASTE LIQUID USING AMYLOLYTIC RHIZOPUS ORYZAE
}

\author{
P.S. PANESAR* and S. KAUR \\ Department of Food Engineering and Technology, Sant Longowal Institute of Engineering and Technology, \\ Longowal-148106, Punjab. India
}

(Received: 11 August 2015; accepted: 13 November 2015)

\begin{abstract}
The utilization of potato waste liquid instead of synthetic substrates for lactic acid production cannot only reduce the production cost but also makes the process environment effective. Unlike many lactic acid bacteria, lactic acid producing Rhizopus strains generates $\mathrm{L}(+)$ lactic acid as a sole isomer of lactic acid. Furthermore, some Rhizopus spp. are amylolytic in nature and can produce lactic acid from starchy substrates without prior saccharification. This study aimed at the utilization of potato waste liquid for the production of $\mathrm{L}(+)$ lactic acid using amylolytic Rhizopus oryzae MTCC 8784. The effect of media components and process parameters on simultaneous saccharification and fermentation of potato waste liquid by fungal strain has been studied to maximize the production of $\mathrm{L}(+)$ lactic acid. The results revealed that highest lactic acid production $\left(15.5 \mathrm{~g} \mathrm{l}^{-1}\right)$ was obtained with potato waste liquid containing $30 \mathrm{~g}^{-1}$ starch supplemented with soya okara hydrolysate $(1.5 \%, \mathrm{v} / \mathrm{v})$, calcium carbonate $(1.5 \%, \mathrm{w} / \mathrm{v})$, and salts. In terms of process parameters, the maximum $\mathrm{L}(+)$ lactic acid $\left(18.15 \mathrm{~g} \mathrm{l}^{-1}\right)$ production was obtained at $\mathrm{pH} 6 \mathrm{with}$ temperature $30{ }^{\circ} \mathrm{C}$, agitation of 150 r.p.m., after incubation period of $48 \mathrm{~h}$.
\end{abstract}

Keywords: potato waste liquid, fermentation, amylolytic, L(+) lactic acid, Rhizopus oryzae

The environmental concerns and legislation has enforced the agro-industries along with researchers to find alternatives for the management of residual by-products. The eco-friendly processing of these residues through biotechnological route and their fermentable capability makes them attractive substrates to produce a range of value added products like lactic acid. It is one of the most important organic acids, which is being extensively used in food, cosmetic, pharmaceutical and chemical industries. The worldwide demand for lactic acid is nearly $300000-400000$ tonnes per year and is projected to be increased rapidly in the near future (NATtrass \& Higson, 2011). Among two optical isomers, i.e. D(-) lactic acid and L(+) lactic acid, $\mathrm{L}(+)$ isomer is generally preferred for food and pharmaceutical industries, since elevated levels of D(-) isomer can be harmful for human consumption (HuANG et al., 2005). Lactic acid was originally produced from pure substrates like glucose, but many investigations have been put forth for its production using agro-industrial residues (GHAFFAR et al., 2014).

In the global context, India is the third largest producer of potatoes and has enough quantity to process them in different products to meet the domestic demand and to earn foreign exchange. Fresh potatoes can be processed into several value added fried and nonfried products like chips, french fries, flakes, etc. (PANDEY et al., 2009). However, during processing of potatoes in food industries, a large amount of wastewater streams has been released. This waste water contains high concentration of organic compounds that are

\footnotetext{
* To whom correspondence should be addressed. Phone: +91-1672-253252; e-mail: pspanesarrr@yahoo.com
} 
responsible for high biological oxygen demand and also responsible for environment pollution, if not properly treated (BERTOLA et al., 1999). The presence of appreciable amount of starch, proteins, vitamins, minerals, and other nutrients in waste water could be utilized cheaply as substrate for the microorganism growth, especially the fungi, which can be further employed for the production of lactic acid.

The lactic acid producing Rhizopus strains are preferred to lactic acid bacteria, as they generate $\mathrm{L}(+)$ lactic acid as a sole isomer of lactic acid, can grow better under nitrogen limited environments, and have easy downstream processing because of their filamentous or pellet forms. Furthermore, fungal cultures, such as Rhizopus spp., are amylolytic and can produce lactic acid from starchy substrates such as potato starch without prior saccharification, which makes the fermentation process cost and time effective. In addition, fungal biomass (by-product of lactic acid fermentation) can be used in several other value added processes, like chitosan production, as additive in animal feeds, and in biosorption processes for purification of contaminated effluents (ZHANG et al., 2007).

The perusal of available literature for utilization of potato waste liquid for $\mathrm{L}(+)$ lactic acid production using Rhizopus strains has been found to be very limited. Keeping this in view, the present study has been undertaken for the production of lactic acid from waste potato starch using amylolytic Rhizopus oryzae strain and to identify the effect of media components and process parameters on simultaneous saccharification and fermentation.

\section{Materials and methods}

\subsection{Procurement and maintenance of microbial strain}

The pure culture of amylolytic Rhizopus oryzae MTCC 8784 was procured from Microbial Type Culture collection Centre, Institute of Microbial Technology (IMTECH), Chandigarh, India. Fungal culture was grown in potato dextrose broth for 7 days and then slants of fungal spores were prepared on potato dextrose agar and stored at $4{ }^{\circ} \mathrm{C}$. Mycelium of freshly grown culture was used as inoculum for lactic acid production.

\subsection{Procurement of potato waste liquid}

Waste potato starch (waste water) was procured from Pepsico India Holdings Pvt. Ltd., FritoLay Division, Channo, Sangrur, Punjab (India). The potato waste liquid was filtered by muslin cloth to remove the solid/suspended particles, sterilized, and stored at $4{ }^{\circ} \mathrm{C}$ till further use. The initial starch concentration in waste water was found to be $54.23 \pm 2.57 \mathrm{~g} \mathrm{l}^{-1}$ with $2.58 \pm 0.49 \%$ sugars, $0.31 \pm 0.03 \%$ protein, $0.24 \pm 0.12 \%$ total dry matter, and $\mathrm{pH} 5.74 \pm 0.26$.

\subsection{Preparation of starter culture}

The spores of Rhizopus oryzae MTCC 8784 were grown on the potato dextrose agar slants at $30{ }^{\circ} \mathrm{C}$ for 7 days and were collected using an inoculation loop and suspended in sterilized distilled water containing Tween $80(1 \mathrm{ml})$. A $250 \mathrm{ml}$ Erlenmeyer flask containing $100 \mathrm{ml}$ of the potato dextrose broth was inoculated with a final concentration of $10^{5}$ spores $/ \mathrm{ml}$ and incubated at $30{ }^{\circ} \mathrm{C}$ for $12 \mathrm{~h}$ with 150 r.p.m. This overnight culture, as seed culture, was used to initiate fungus growth in potato waste liquid containing fermentation medium. 


\subsection{Fermentation medium}

The fermentation medium comprised of potato waste liquid $(100 \mathrm{ml})$ having soya okara hydrolysate (1\%, v/v); $\mathrm{KH}_{2} \mathrm{PO}_{4}(200 \mathrm{mg}, \mathrm{w} / \mathrm{v}), \mathrm{MgSO}_{4}(200 \mathrm{mg}, \mathrm{w} / \mathrm{v})$, and calcium carbonate $(1 \%, \mathrm{w} / \mathrm{v})$. Soya okara hydrolysate was prepared by treating dry soya okara powder $(28 \pm 2.14 \%$ crude protein) with $0.75 \%$ of concentrated $\mathrm{H}_{2} \mathrm{SO}_{4}$ and heated in water bath at $70{ }^{\circ} \mathrm{C}$ for about $4 \mathrm{~h}$ and then filtered using muslin cloth. The filtrate was used for fermentation after neutralizing the $\mathrm{pH}$ to 7.0. The fermentation medium was autoclaved at $121{ }^{\circ} \mathrm{C}$ for $20 \mathrm{~min}$, inoculated with aliquots $3 \mathrm{ml}$ of seed culture (unless or otherwise specified) and further incubated at $30{ }^{\circ} \mathrm{C}$ for $72 \mathrm{~h}$ at 100 r.p.m.

\subsection{Optimization of media components and process parameters}

The concentration of media components like starch content $\left(10-50 \mathrm{~g} \mathrm{l}^{-1}\right)$, soya okara hydrolysate $(0.5-2.5 \%, \mathrm{v} / \mathrm{v})$, and calcium carbonate $(0.5-3 \%, \mathrm{w} / \mathrm{v})$ was varied in fermentation media to study the effect of individual component on lactic acid production using potato waste liquid by $R$. oryzae MTCC 8784 . The flasks were further incubated at $30{ }^{\circ} \mathrm{C}$ with agitation of 100 r.p.m. and incubation period of 72 h (Orbital Shaking Incubator, MAC, Macro Scientific Works Pvt. Ltd., India).

The effect of different process parameters like $\mathrm{pH}$ (4.0-7.0), incubation temperature $\left(25-40{ }^{\circ} \mathrm{C}\right)$, inoculum size $(1-5 \mathrm{ml}$ of seed culture), agitation rate (50-200 r.p.m.), and incubation time (12-72 h) has been studied to find the optimum values, which can maximize the lactic acid production using potato waste liquid.

\subsection{Analytical techniques}

The fermented broth obtained after centrifugation of fungal mycelium was used for the determination of lactic acid and residual starch content. Lactic acid estimation was accomplished using high performance liquid chromatograph (HPLC) system (Shimadzu, Asia Pacific, PTE Ltd, Singapore) following the method of KisHORE and co-workers (2013). Samples were filtered by $0.20 \mu \mathrm{m}$ membrane filters and lactic acid concentration has been estimated by HPLC using C18 column and UV detector with absorbance at $210 \mathrm{~nm}$. The mobile phase was prepared with $10 \mathrm{mM}$ phosphate buffer (95\%) containing acetonitrile (5\%)

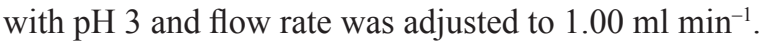

Starch content was measured by iodine method, in which fermentation broth $(10 \mathrm{ml})$ was centrifuged to pellet out the fungal mycelium and supernatant was diluted 5 times with distilled water. To $10 \mathrm{ml}$ of the sample, $1 \mathrm{ml}$ of iodine solution $(0.15 \%$ iodine $+1.5 \%$ potassium iodide) was added. The mixture was vortexed and the absorbance of the resultant blue coloured complex was measured at $585 \mathrm{~nm}$ with spectrophotometer (NAKAMURA, 1981). The starch degradation was calculated by subtracting the starch content of the sample from un-inoculated broth, whereas the concentration of the residual starch in each of the supernatant was determined from a standard curve.

\section{Results and discussion}

The simultaneous saccharification and fermentation for lactic acid production by $R$. oryzae 8784 using potato waste liquid was studied with respect to different media compositions and process parameters. The results obtained during different experimentation have been discussed in subsequent paragraphs.

Acta Alimentaria 46, 2017 


\subsection{Effect of starch concentration}

Starch has been considered as raw material for various fermentation processes because of its abundance and low price. However, when high concentration of starch is used in medium, an increase in viscosity of the medium due to gelatinization by heat will reduce the microbial growth. Therefore, the potato waste liquid containing different concentrations of starch has been utilized for $\mathrm{L}(+)$ lactic acid production. The results revealed that the concentration of lactic acid and starch degradation initially increased with an increase in starch content present in potato waste liquid media but then decreased. The starch concentration up to $30 \mathrm{~g} \mathrm{l}^{-1}$ was utilized by the $R$. oryzae MTCC 8784 to give highest lactic acid $\left(13.56 \mathrm{~g} \mathrm{l}^{-1}\right)$ production and starch utilization $(52.49 \%, \mathrm{w} / \mathrm{v})$ as shown in Figure 1. The results were comparable with previous reports, in which the highest yield of lactic acid was obtained as the starch concentration varied from 20 to $40 \mathrm{~g} \mathrm{l}^{-1}$, as this starch is more accessible to the enzymes secreted during the fungal growth (JIN et al., 2003).

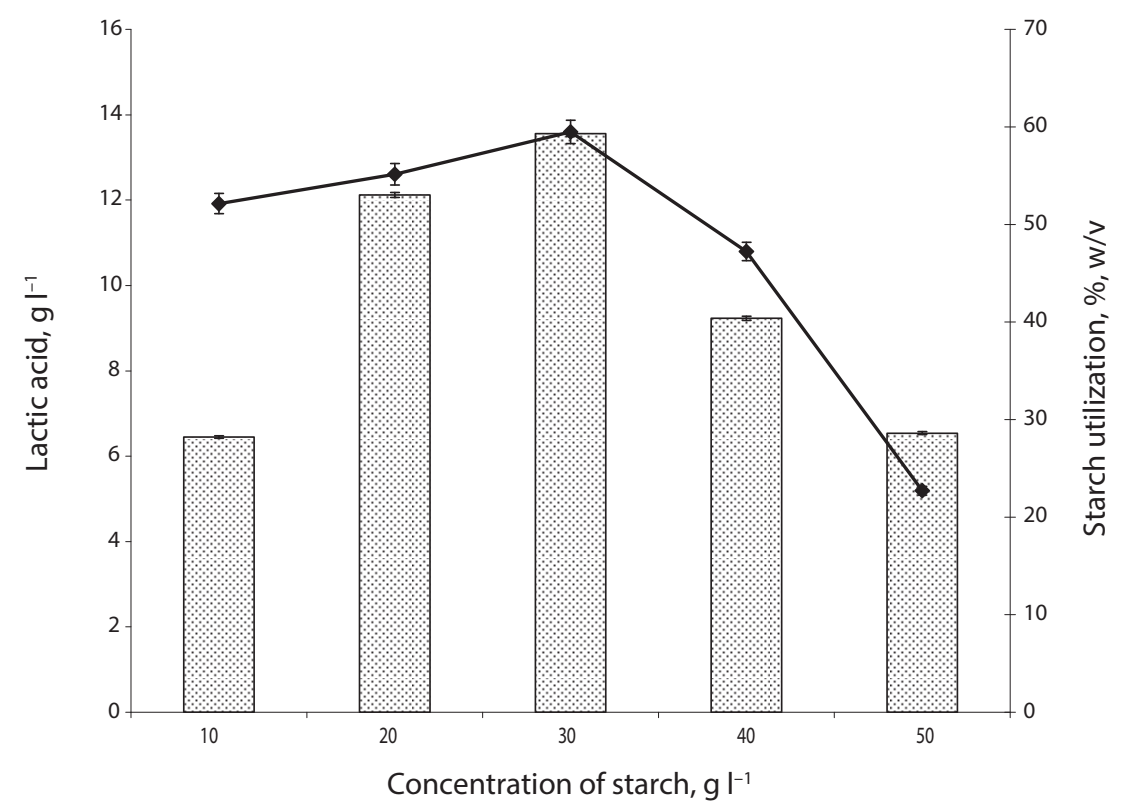

Fig. 1. Effect of starch concentration on lactic acid production using potato waste liquid by $R$. oryzae MTCC 8784 : lactic acid, $\mathrm{g} \mathrm{l}^{-1}$

\subsection{Effect of nitrogen concentration}

Okara, a by-product of soya milk and tofu has been reported to be rich in protein (4.8\%), fat $(3.6 \%)$, starch and sugar $(6.4 \%)$, and fibre $(3.3 \%)$ making it a potentially suitable substrate for microbial fermentation (Li et al., 2013). Therefore, the concentration of soya okara hydrolysate as a cheap nitrogen source has been varied from $0.5-2 \%(\mathrm{v} / \mathrm{v})$ for the production of L(+) lactic acid by $R$. oryzae MTCC 8784 . The maximal values for lactic acid production $\left(14.12 \mathrm{~g} \mathrm{l}^{-1}\right)$ and starch utilization $(57.21 \%)$ were observed with $1.5 \%(\mathrm{v} / \mathrm{v})$ soya okara 
hydrolysate and further the trend was reversed (Fig. 2). The utilization of pure nitrogen source like yeast extract, urea, peptone, etc. for lactic acid production may be economically unfavourable, because lactic acid is relatively a cheap product. To replace these refined and costly sources, the application of agricultural resources is promising to be used as an alternate (TANAKA et al., 2006). Moreover, addition of nitrogen source in fermentation media enhances mycelium growth and promotes lactic acid production(YUWA-AMORNPITAK \& CHOOKIETWATTANA, 2014).

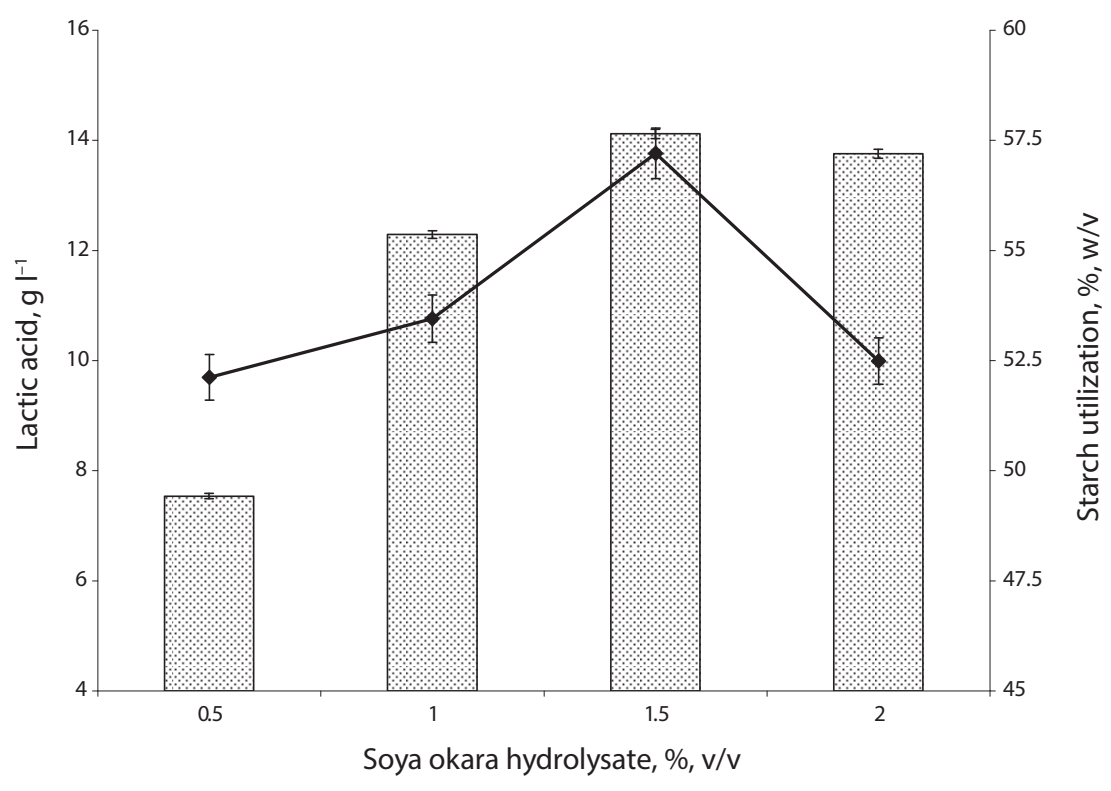

Fig. 2. Effect of soya okara hydrolysate concentration on lactic acid production using potato waste liquid by $R$. oryzae MTCC 8784 : lactic acid, $\mathrm{g}^{-1}$;

\subsection{Effect of calcium carbonate}

Neutralizing agents are generally added during lactic acid production, as high production of acid can decrease the $\mathrm{pH}$ of fermentation medium, which further affects the microbial growth. Therefore, addition of calcium carbonate $\left(\mathrm{CaCO}_{3}\right)$ retards the extreme decline of medium acidity (KuRNiaWATI et al., 2014). During optimization of $\mathrm{CaCO}_{3}$ concentration, the lactic acid production $\left(15.5 \mathrm{~g} \mathrm{l}^{-1}\right)$ was found to be increasing with an increase of $\mathrm{CaCO}_{3}$ up to $1.5 \%$ (Fig. 3). The supplementation of $1.0 \%(\mathrm{w} / \mathrm{v})$ of $\mathrm{CaCO}_{3}$ has been reported to be sufficient for maintaining a growth $\mathrm{pH}$ to achieve an optimum cell growth and lactic acid production by Rhizopus cultures (HuANG et al., 2005). 


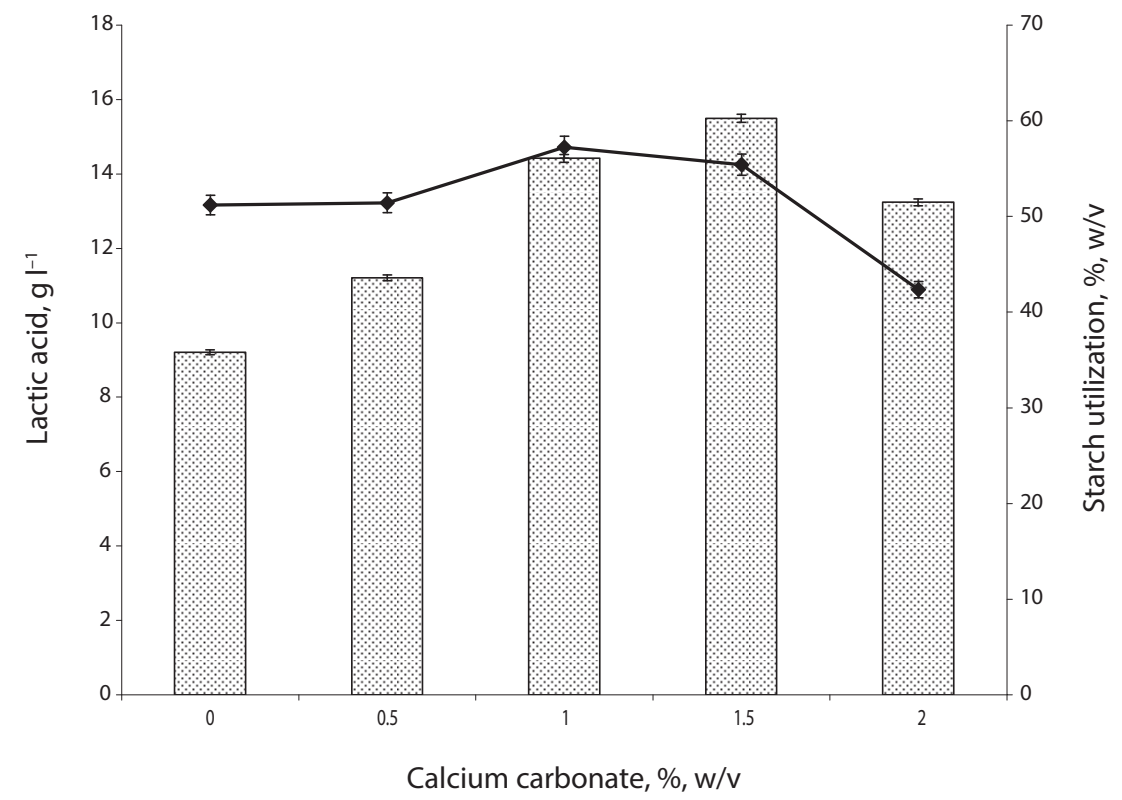

Fig. 3. Effect of calcium carbonate concentration on lactic acid production using potato waste liquid by $R$. oryzae MTCC 8784 : lactic acid, $\mathrm{g}^{-1}$; starch utilization, $\%, \mathrm{w} / \mathrm{v}$

\subsection{Effect of $p H$ and temperature}

The effects of hydrogen ion concentration $(\mathrm{pH} 4.0-7.0)$ and temperature $\left(25-40{ }^{\circ} \mathrm{C}\right)$ to enhance lactic acid production using $R$. oryzae MTCC 8784 were evaluated. The production increased with an increase in $\mathrm{pH}$, however, the highest production of lactic acid $\left(15.5 \mathrm{~g} \mathrm{l}^{-1}\right)$ was observed at $\mathrm{pH} 6$, and further increase in $\mathrm{pH}$ lead to decrease in lactic acid production (Fig. 4). The results also indicated that starch utilization was better at $\mathrm{pH}$ 6, which revealed that $R$. oryzae MTCC 8784 had a high enzymatic capability for saccharification of potato waste liquid at $\mathrm{pH} 6$. The results are in agreement with previous reports, where Rhizopus sp. had a high enzymatic capability for saccharification of leftover bits and pieces of potato starch in the pH range of 4.8-7.0 (SHI et al., 2013). 


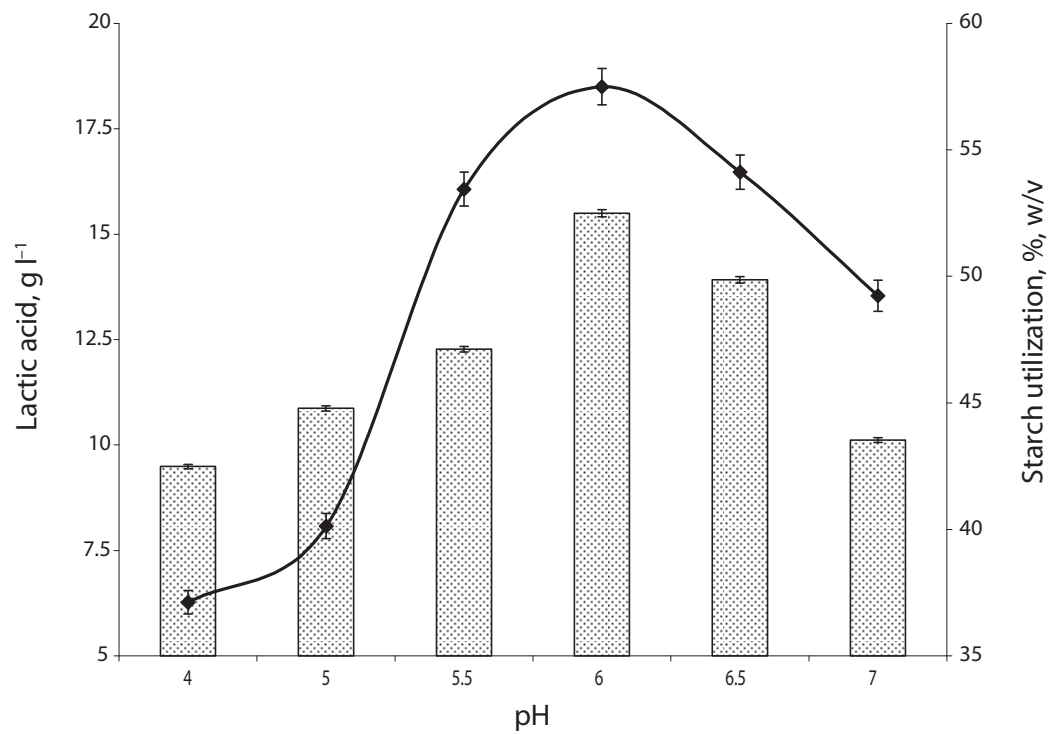

Fig. 4. Effect of $\mathrm{pH}$ on lactic acid production using potato waste liquid by $R$. oryzae MTCC 8784 :: lactic acid, $\mathrm{g}^{-1}$; : starch utilization, $\%, \mathrm{w} / \mathrm{v}$

The impact of the cultivation temperature on fermentation revealed that $\mathrm{L}(+)$ lactic acid production $\left(15.5 \mathrm{~g}^{-1}\right)$ and starch utilization $(57.53 \%$, w/v) by $R$. oryzae MTCC 8784 was achieved best at $30{ }^{\circ} \mathrm{C}$ (Fig. 5). Temperature is found to be an important process operation factor that affects lactic acid production, where for Rhizopus sp. fermentation temperature in a range of $27-35{ }^{\circ} \mathrm{C}$ has been used widely in previous investigations (RUENGRUGLIKIT \& HANG, 2003; PARK et al., 2004; HuANG et al., 2005).

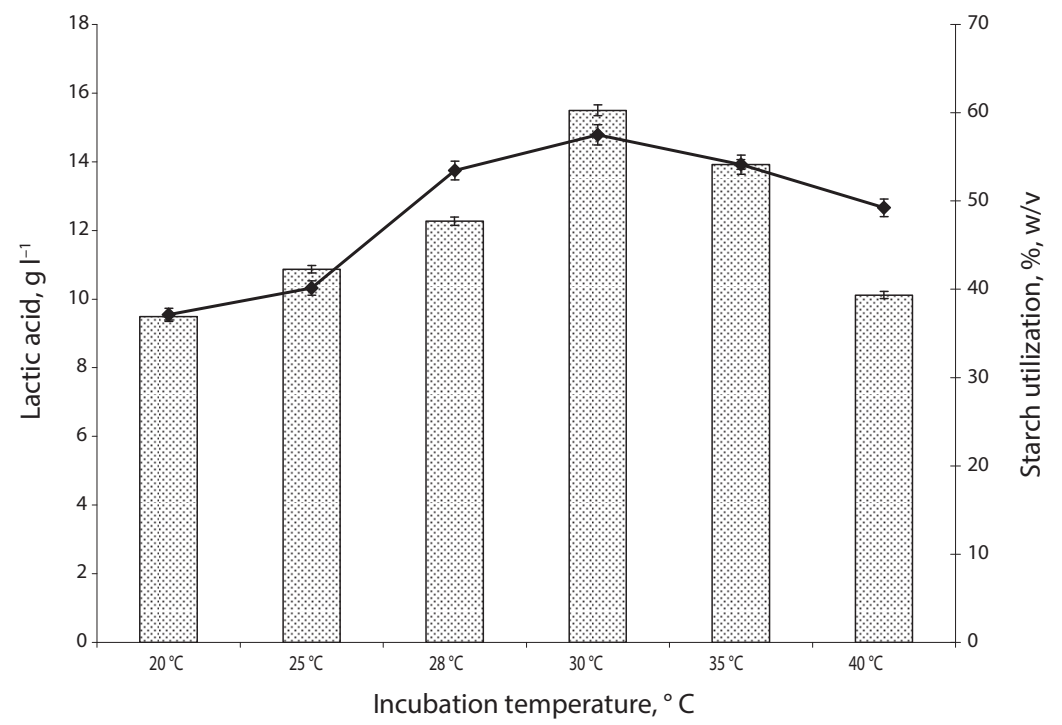

Fig. 5. Effect of incubation temperature on lactic acid production using potato waste liquid by $R$. oryzae MTCC 8784 : lactic acid, $\mathrm{g} \mathrm{l}^{-1} ; \multimap$ : starch utilization, \%, w/y 
Effect of inoculum size. The influence of inoculum size (based on concentration of seed culture) on lactic acid production has been investigated. The results showed that lactic acid production $\left(17.12 \mathrm{~g} \mathrm{l}^{-1}\right)$ increased with an increase of seed culture concentration up to $4 \mathrm{ml}$ and then decreased (Fig. 6). The decrease in lactic acid production and starch utilization at high inoculum size may be due to the formation of irregular masses of fungal mycelium in the fermentation medium at high concentration, which may further limit the nutrient and dissolved oxygen uptake.

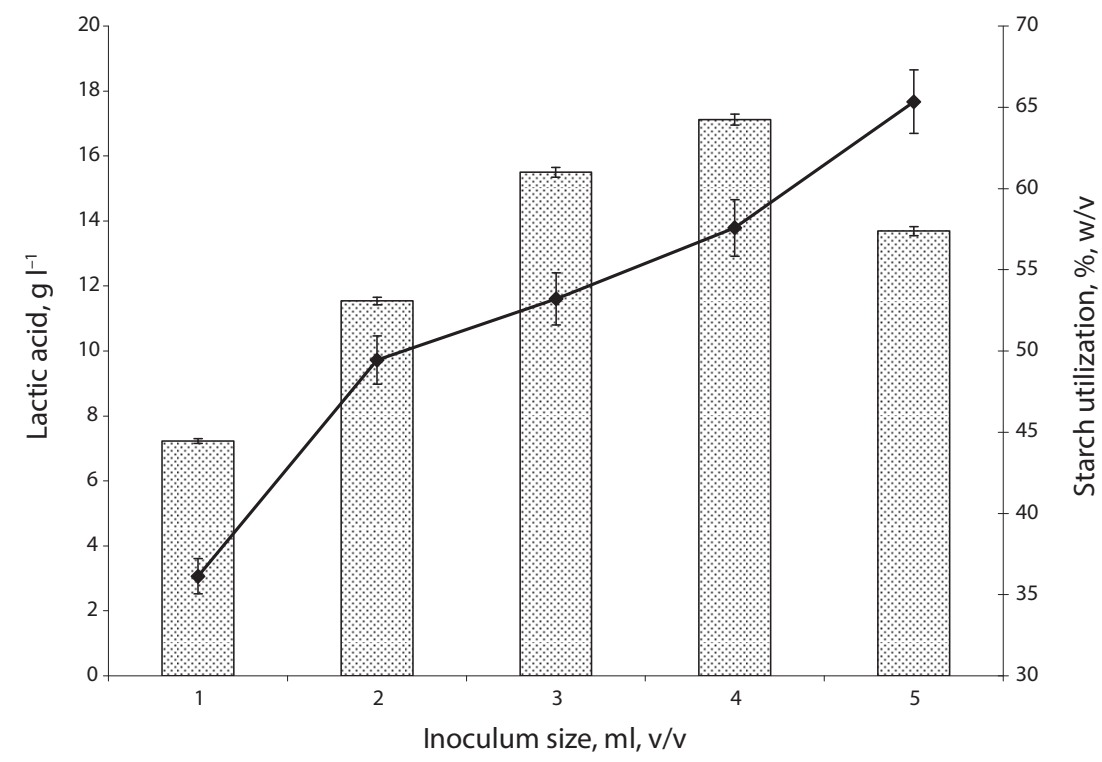

Fig. 6. Effect of inoculum size on lactic acid production using potato waste liquid by $R$. oryzae MTCC 8784 : lactic acid, $\mathrm{g}^{-1}$;

Effect of agitation. Fungal cultures especially moulds need high agitation rate for their growth and product formation. Therefore, the effect of agitation speed (50-200 r.p.m.) on lactic acid production by $R$. oryzae MTCC 8784 was screened. It has been observed that lactic acid $\left(17.95 \mathrm{~g} \mathrm{l}^{-1}\right)$ was produced with highest rate at 150 r.p.m. (Fig. 7). However, further increase in agitation resulted in decreased production of lactic acid, which may be due to that high shear stresses with increasing agitation speed can cause undesirable effects on mycelial cell growth, biomass formation, and product yield (MARTAK et al., 2003). 


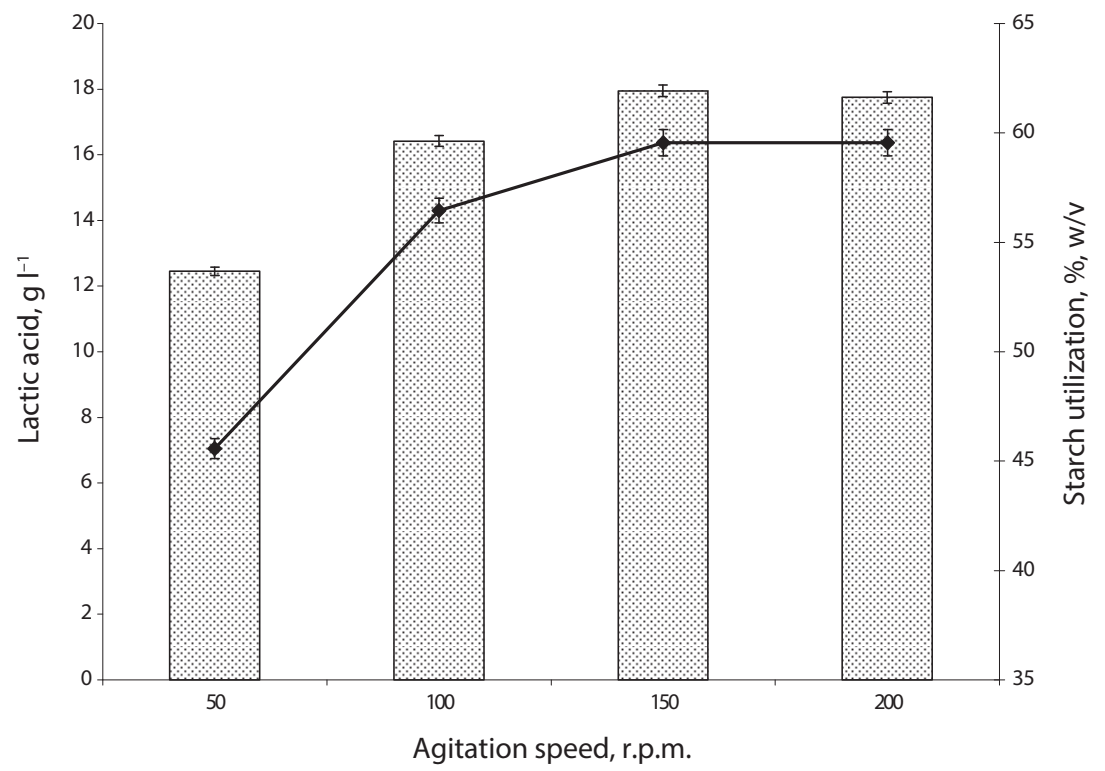

Fig. 7. Effect of agitation on lactic acid production using potato waste liquid by R. oryzae MTCC 8784 : lactic acid, $\mathrm{g}^{-1} ; \longrightarrow$ : starch utilization, $\%, \mathrm{w} / \mathrm{v}$

Effect of incubation time. Rhizopus oryzae MTCC 8784 produced maximum lactic acid (18.15 $\left.\mathrm{g} \mathrm{l}^{-1}\right)$ after $48 \mathrm{~h}$ of incubation period with starch utilization of $60.14 \%$ (w/v). It was also observed that starch was maximally utilized $(65.12 \%)$ after $72 \mathrm{~h}$ but the lactic acid production decreased after $48 \mathrm{~h}$ (Fig. 8). Moreover, the growth curve of $R$. oryzae MTCC 8784 showed maximum cell biomass $\left(57.12 \mathrm{~g} \mathrm{l}^{-1}\right.$, wet basis) after $72 \mathrm{~h}$ of incubation period at $30{ }^{\circ} \mathrm{C}$ (Fig. 8). These phenomena may be explained by that a fast starch hydrolysis resulted in producing high quantity of reducing sugars, in particular glucose, leading to a fast fungal cell growth. On the other hand, the high glucose accumulated may inhibit the lactic acid formation (HuANG et al., 2005). Therefore, it is important to find the optimal incubation time to control the fermentation process to maximize lactic acid production. 


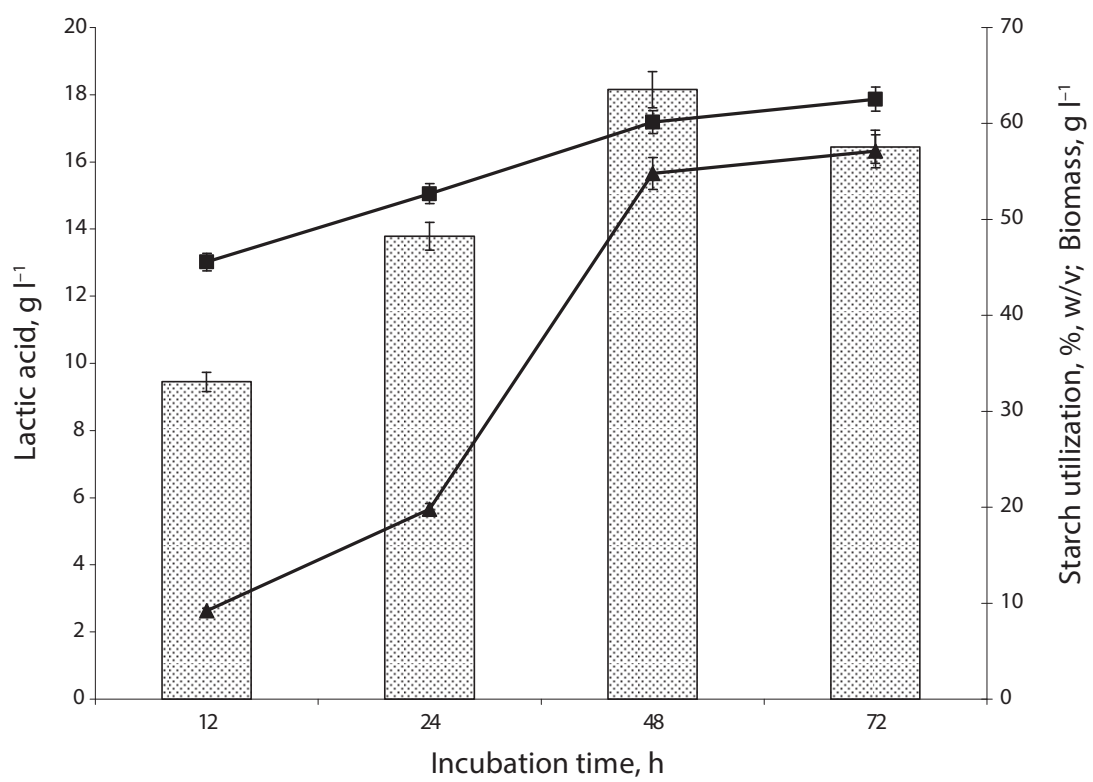

Fig. 8. Effect of incubation time on lactic acid production using potato waste liquid by R. oryzae MTCC 8784 : lactic acid, $\mathrm{g}^{-1} ; \multimap$ : starch utilization, $\% \mathrm{w} / \mathrm{v} ; \multimap$ : biomass (wet basis) $\mathrm{g}^{1^{-1}}$

\section{Conclusions}

Rhizopus oryzae MTCC 8784 showed good amylolytic activity to produce lactic acid from starchy waste substrates without prior saccharification. Optimization of media components and process parameters enhanced the performance of Rhizopus species in lactic acid production and starch utilization. The effect of media components revealed highest production of lactic acid $\left(15.5 \mathrm{~g} \mathrm{l}^{-1}\right)$ with potato waste liquid supplemented with soya okara hydrolysate, salts, and calcium carbonate. In terms of process parameters, the maximum $\mathrm{L}(+)$ lactic acid production (18.15 $\mathrm{g} \mathrm{l}^{-1}$ ) was obtained after $48 \mathrm{~h}$ using Rhizopus oryzae MTCC 8784.

The authors acknowledge the financial support given by the Council for Scientific and Industrial Research (CSIR), New Delhi, India

\section{References}

Bertola, N., Palladino, L., Bevilacqua, A. \& Zaritzky, N. (1999): Optimization of the design parameters in an activated sludge system for the wastewater treatment of a potato processing plant. J. Food Eng., 40, 27-33.

Ghaffar, T., Irshada, M., Anwara, Z., Agilb, T., Zulifqara, Z., Taripa, A., Kamrana, M., Ehsana, N. \& Mehmooda, S. (2014): Recent trends in lactic acid biotechnology: A brief review on production to purification. J. Rad. Res. Appl. Sci. (JRRAS), 7, 222-229.

Huang, L.P., JiN, B., LANT, P. \& Zhou, J.T. (2005): Simultaneous saccharification and fermentation of potato starch waste water to lactic acid by Rhizopus oryzae and Rhizopus arrhizus. Biochem. Eng. J., 23, 265-276.

Jin, B., Huang, L.P. \& Lant, P. (2003): Rhizopus arrhizus - a producer for simultaneous saccharification and fermentation of starch waste materials to L(+)-lactic acid. Biotechnol. Lett., 25, 1983-1987. 
Kishore, G., Karthik, A., Gopal, S.V., Kumar, A.R., Bhat, M. \& Udupa, N. (2013): Development of RP-HPLC method for simultaneous estimation of lactic acid and glycolic acid. Der Pharma Chemica, 5, 335-340.

Kurniawati, T., Indrati, R. \& Sarrdjono (2014): Isolation of Rhizopus oryzae from rotten fruit and its potency for lactic acid production in glucose medium with and without addition of calcium carbonate. Agritech, 34, 170176.

Li, S., Zhu, D., Li, K., Yang, Y., Lei, Z. \& Zhang, Z. (2013): Soybean curd residue: composition, utilization, and related limiting factors. ISRN Ind. Eng., 2013, 1-8.

Martak, J., Schlosser, S., Sabolova, E., Kristofikova, L. \& Rosenberg, M. (2003): Fermentation of lactic acid with Rhizopus arrhizus in a stirred tank reactor with a periodical bleed and feed operation. Process Biochem., 38, 1573-1583.

NAKAMURA, L.K. (1981): Lactobacillus amylovorus, a new starch-hydrolyzing species from cattle waste-corn fermentations. Int. J. Syst. Bacteriol., 31(1), 56-63.

NATTRAss, L. \& Higson, A. (2011): NNFCC Renewable chemicals fact sheet: Lactic acid, United Kingdom. http:// www.nnfcc.co.uk/publications/nnfcc-renewable-chemicals-factsheet-lactic-acid (last accessed 13 November 2015)

Pandey, S.K., Marwaha, R.S., Kumar, D. \& Singh, S.V. (2009): Indian potato processing story: industrial limitations, challenges ahead and vision for the future. Potato J., 36, 1-13.

PArk, E.Y., Anh, P.H. \& OHudA, N. (2004): Bioconversion of waste office paper to L(+) lactic acid by the filamentous fungus Rhizopus oryzae. Bioresource Technol., 93, 77-83.

Ruengruglikit, C. \& Hang, Y.D. (2003): L(+)-Lactic acid production from corncobs by Rhizopus oryzae NRRL395. LWT-Food Sci. Technol., 36, 573-575.

Shi, G., Wang, G., Chen, X. \& Li, C. (2013): Optically pure L-lactic acid production directly from leftover bits and pieces of potato starch using an amylolytic pellet-form complex Rhizopus oryzae ASC081. J. Appl. Sci. Eng., $16,205-210$

Tanaka, T., Hoshina, M., Tanabe, S., Sakai, K., Ohtsubo, S. \& Taniguchi, M. (2006): Production of D-lactic acid from defatted rice bran by simultaneous saccharification and fermentation. Bioresource Technol., 97, 211217.

Yuwa-Amornitak, T. \& Chookietwattana (2014): L-lactic acid production from cassava starch by thermotolerant Rhizopus microspores LTH23. J. Biol. Sci., 14, 284-291.

Zhang, Z.Y., Jin, B. \& Kelly, M.J. (2007): Production of lactic acid from renewable materials by Rhizopus fungi. Biochem. Eng. J., 35, 251-263. 